\title{
A decision-making guide for the closure of myelomeningocele skin defects with or without primary repair
}

\author{
Cemal Alper Kemaloğlu, MD, İrfan Özyazgan, MD, and Ömer Faruk Ünverdi, MD \\ Department of Plastic, Reconstructive, and Aesthetic Surgery, Erciyes University, Kayseri, Turkey
}

\begin{abstract}
OBJECTIVE The closure of the skin defect in myelomeningocele (MMC) repair is an essential step that determines the quality of the surgical result. The success of surgical results is related to the decision to use the most suitable techniques, namely flaps or primary closure. The aim of this study was to evaluate the effectiveness of a decision-making guide to determine whether to use primary repair or a flap for the closure of skin defects that occur in MMC.
\end{abstract}

METHODS Fifty patients underwent surgery after neurosurgical repair and closure of the placode. A simple guide was generated according to the defect height/width and posterior axillary lines/defect width ratio. These 2 ratios were considered to determine which closure technique (with or without primary repair) should be used for the MMC defect reconstruction.

RESULTS By using this decision-making guide, 20 of the defects were repaired with various flaps, and those of the remaining 30 patients were repaired with primary closure. In all patients, a successful tension-free 1-stage closure was obtained. Except for 4 patients who had flap reconstruction with partial flap necrosis or minimal flap tip necrosis, healing was uneventful without any complications. There were no additional wound complications during the mean follow-up of 6.8 years (range 5 months to 14 years).

CONCLUSIONS Because of various defect sizes and patient characteristics, no single protocol exists for the reconstruction of MMC defects. The guide suggested here might be effective in deciding which method is suitable for closure of MMC skin defects.

http://thejns.org/doi/abs/10.3171/2016.2.PEDS15702

KEY WORDS myelomeningocele; primary closure; fasciocutaneous flaps; musculocutaneous flaps; congenital

$\mathrm{M}$ YELOMENINGOCELE (MMC) is the most complex congenital malformation of the CNS that is compatible with life. Although the incidence is declining as a result of prenatal screening for neural tube defects, MMC remains a common congenital anomaly seen in approximately 1 in 1000 live births..$^{19}$ The lumbosacral area is the site of approximately three-quarters of cases. Early closure of MMC defects is advocated because it reduces infection rates even though it is not associated with improved neurological outcome. ${ }^{8}$

Several methods of skin coverage for large MMCs have been described. These include the following: primary closure; wide undermining with skin advancement; cutaneous flaps with primary closure of the secondary defect; cutaneous flaps with split skin grafting of secondary defects (rotation, transposition, bipedicle); transposed muscle flaps with split skin grafting of the primary defect (latissimus dorsi, gluteus, trapezius); musculocutaneous flaps with split skin grafting of the secondary defect; bone and muscle flaps with split skin grafting of the primary defect; and split skin graft to formal dural repair., ${ }^{7,911,13,21}$

Despite the fact that several reconstructive techniques have been described for closure of the MMC defect, there is no decision-making guide in the literature on whether to use a flap or primary closure for the reconstruction of all types of these skin defects.

In addition to the defect's size, its shape and the amount of adequate soft tissue around the defect are also important 
for the reconstruction. Therefore, in this article we present a simple decision-making guide, which can be used to decide whether the closure of MMC skin defects should be performed by primary repair or flap and thus achieve reduced morbidity by not performing flap surgery unnecessarily.

\section{Methods}

This study protocol was approved by the ethics committee at our institution, and written informed consent was obtained from each patient's parent. Between February 2001 and June 2015, 50 infants born with large thoracolumbar and lumbosacral MMC defects, with sizes ranging from $5 \times 4 \mathrm{~cm}$ to $12.5 \times 9 \mathrm{~cm}$, underwent excision of the MMC sac and dural repair, followed by immediate reconstruction. Before starting closure, defect width (x values), defect height ( $\mathrm{y}$ values), and distance between posterior axillary lines ( $2 \mathrm{z}+\mathrm{x}$ values) were measured in all patients. Then, the $y / x$ and $2 z+x / x$ ratios were calculated. According to our decision-making guide, these 2 ratios are considered to determine which closure technique (with or without primary repair) should be used.

\section{Decision-Making Guide}

Figure 1 illustrates the following points of our decisionmaking guide for determining which closure technique to use for MMC defect reconstruction.

1) If the defect height/width $(y / x)$ ratio is $\geq 1.5$, then 2 parameters are evaluated: a) if the length between the posterior axillary lines/defect width $(2 \mathrm{z}+\mathrm{x} / \mathrm{x})$ ratio is $\geq$ 3 , then primary closure is indicated; and $b$ ) if the length between the posterior axillary lines/defect width $(2 \mathrm{z}+$ $\mathrm{x} / \mathrm{x}$ ) ratio is $<3$, then closure by flap is indicated.

2) If the defect height/width $(y / x)$ ratio is $<1.5$, then closure by flap is indicated.

All patients were operated on by 2 surgeons (C.A.K. and İ.Ö.). In patients who had primary closure, undermining was done up to the posterior axillary line and 2 flaps were sutured at the midline. However, in patients who had flap reconstruction, a single Limberg, 2 Limberg, 3 Limberg, or bipedicled fasciocutaneous flaps were used. Before raising the flaps, adrenaline in saline $(1: 200,000)$ was injected subcutaneously along the line of the incision, and the flaps were then raised over the back muscles and sutured in a tension-free manner.

The patients' ages at the time of surgery ranged from 1 to 5 days (mean 2.4 days), and all patients had flaccid paralysis of both lower extremities. Ten patients (20\%) had associated anatomical defects other than an MMC, including club feet, hydrocephalus, and Chiari malformation. The mean follow-up was 6.8 years (range 5 months to 14 years).

\section{Results}

Of these 50 infants, 21 were girls and 29 were boys. The localization of the defect was the thoracolumbar region in 8 patients and the lumbosacral region in 42 patients. The average defect sizes in the primary-closure and the flapreconstructed groups were $46.9 \mathrm{~cm}^{2}$ and $66.7 \mathrm{~cm}^{2}$, respec-
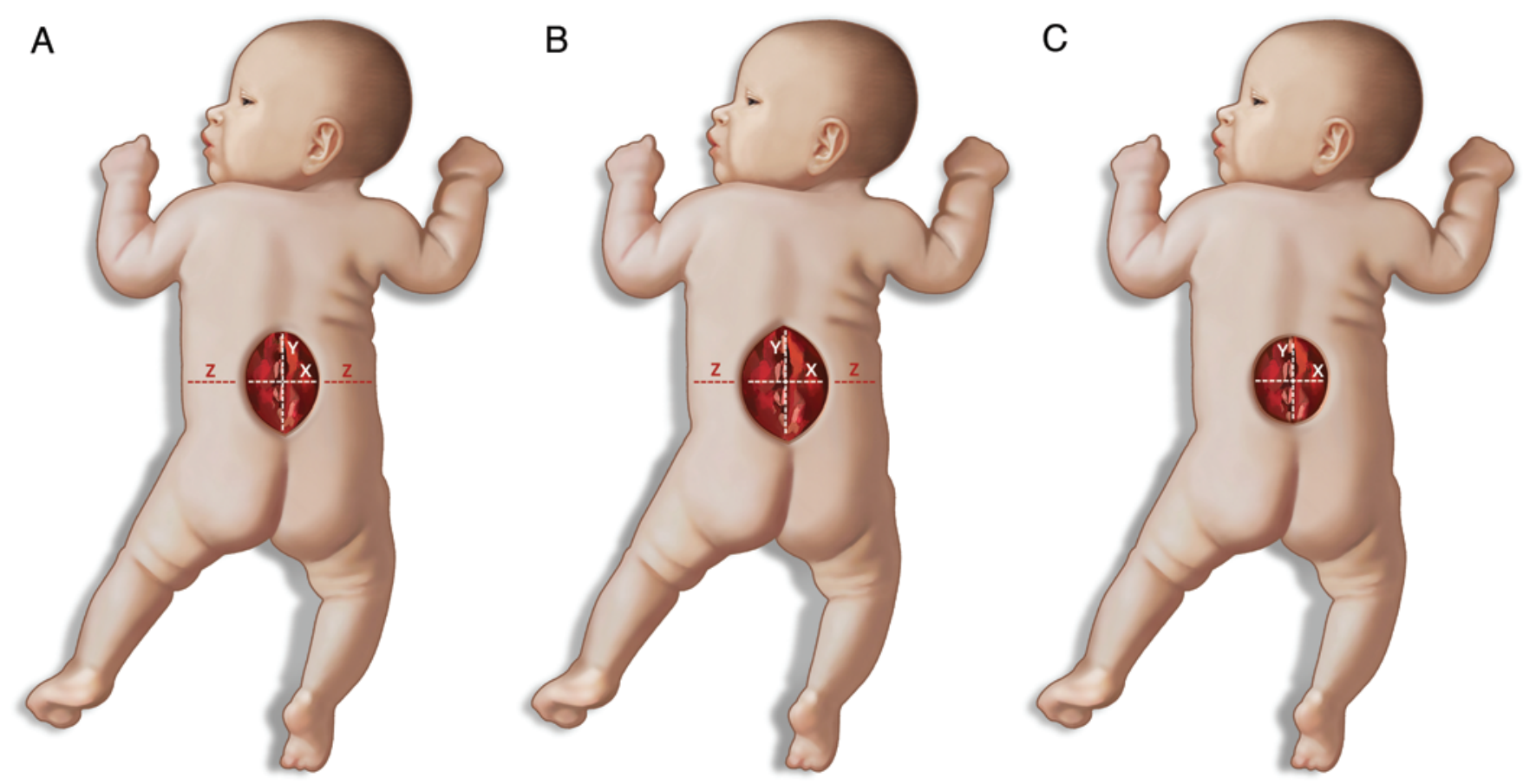

FIG. 1. If the defect height $(y) /$ width $(x)$ ratio is $\geq 1.5$, then 2 parameters are evaluated. A: If the length between posterior axillary lines $(2 z+x) /$ defect width $(x)$ is $\geq 3$, then primary closure is indicated. B: If the length between posterior axillary lines $(2 z+x) / d e-$ fect width $(x)$ is $<3$, then closure by flap is indicated. C: If the defect height $(y) /$ width $(x)$ is $<1.5$, then closure by flap is indicated. Copyright Ali Saraçoğlu. Published with permission. Figure is available in color online only. 
tively. By using our decision-making guide, the defects of 30 patients were closed with primary closure, and those of the remaining 20 patients were closed with flap surgery. In the flap-reconstructed group, 3 patients were operated on with a single-Limberg flap, 13 patients with 2-Limberg flaps, 1 patient with 3-Limberg flaps, and 3 patients with a bipedicled flap. Despite the fact that the average defect height/width ratio and the average length between the posterior axillary lines/defect width ratio were 1.6 and 3.2 in the primary-closure group, the same ratios were 1.3 and 1.8 in the flap-reconstructed group. Detailed values and ratios are shown in Table 1.

A successful tension-free closure of the defect was obtained in all patients. All patients tolerated the procedure without blood transfusion and without perioperative complications. During the follow-up period, among 4 patients who had flap reconstruction, partial flap necrosis developed in 2 patients and minor flap tip necrosis developed in the other 2 patients. The patients who had partial flap necrosis were managed by debridement of all the necrotic tissue, and latissimus dorsi flap reconstruction was performed over the defect. The 2 cases of minor flap tip necrosis were healed by daily dressing changes, and the tissue underwent secondary healing. Except for these 4 patients, all patients healed with no recorded skin flap separation, skin flap dehiscence, skin flap necrosis, infection, CSF leak, or a need for further surgery. The average defect sizes, type of reconstruction, and complications are shown in Table 2.

All patients were discharged 12-14 days postoperatively. Suture removal was performed 12-14 days postoperatively, and patients were evaluated every 2 weeks for assessment of long-term results. The mean follow-up was 6.8 years; all patients had stable and reliable wound coverage and none had any complications or morbidity related to the procedure (Figs. 2 and 3).

\section{Discussion}

Defects of the neural tube result from failure of the spinal tube to close during the 1st month of gestation, and they vary in severity from anencephaly to occult spina bifida. Folic acid deficiency, genetics, and geographic factors, together with low socioeconomic standards, are possible causes for these lesions. ${ }^{3,12}$ There is experimental and clinical evidence that in utero repair of MMCs may preserve neurological function. ${ }^{15}$ However, this option is available in only a few centers; closure of an MMC defect is usually performed during the first hours after birth.

There are many techniques available in the armamentarium of the plastic surgeon that can be useful for the closure of MMC defects. Regardless of the technique used, it should be tension free, provide good soft-tissue padding of the neural tube, prevent CSF leakage, and provide stable and durable wound healing, especially for large defects. Additionally, the techniques used to reconstruct the defect should result in less morbidity.

From the literature, it is seen that several authors prefer musculocutaneous flaps for managing neonates with large MMC defects, but it is recognized that musculocutaneous flap coverage of large lumbosacral MMC defects is associated with high complication rates. ${ }^{4,16}$ Additionally, compared with musculocutaneous flaps, the dissection of local skin flaps is much easier to perform, requires less operative time, and results in less blood loss. Thus, several authors prefer using skin flaps such as advancement flaps, bipedicled flaps, local transposition flaps, bilobed flaps, double Z-plasty, rotation flaps, and Limberg flaps, which can be used successfully in the closure of large MMC defects. ${ }^{1,2,5,6,17}$ We reserved muscle flap usage for the management of complications. Only 2 patients who had partial flap necrosis underwent latissimus dorsi flap reconstruction.

The Limberg flap is a fasciocutaneous transpositional flap that is raised around the defect. This flap is one of the most popular procedures in the reconstruction of MMCs. ${ }^{16}$ In contrast to musculocutaneous flaps, the Limberg flap does not disrupt the back muscles and the donor area can be closed primarily. In this way, morbidity related to muscle disruption is prevented and the maintenance of trunk posture is better achieved at a later stage. In our study, various kinds of Limberg flaps were used successfully, such as a single, double, or triple Limberg flap, according to the defect size. To achieve tension-free closure in large defects, a double or triple Limberg flap was preferred to a single one. Similarly, the bipedicled flap is a fasciocutaneous flap, but it is perfused by a superior and inferior pedicle. We used a bipedicled flap in only 3 patients to show that various kinds of flaps can be used in this guide, according to the surgeon's preference.

Primary closure is possible by undermining of the wound margins in almost $75 \%$ of cases. However, the remaining $25 \%$ of patients with large defects require a more complex procedure. ${ }^{6,18,21}$ In the literature, flap reconstruc-

TABLE 1. Values for defect width, defect height, and ratios for defect height/width, posterior axillary lines/defect width among patients with MMCs

\begin{tabular}{llccccc}
\hline \multirow{2}{*}{ Type of Repair } & Type of Flap & No. of Pts & $\begin{array}{c}\text { Mean } \mathrm{x} \text { in } \mathrm{cm} \\
\text { (range) }\end{array}$ & $\begin{array}{c}\text { Mean y in cm } \\
\text { (range) }\end{array}$ & $\begin{array}{c}\text { Mean y/x in cm } \\
\text { (range) }\end{array}$ & $\begin{array}{c}\text { Mean } 2 z+x / x \text { in } \mathrm{cm} \\
\text { (range) }\end{array}$ \\
\hline Primary closure & NA & 30 & $4.8(4-5.3)$ & $7.7(6-12)$ & $1.6(1.5-2.4)$ & $3.2(3-3.5)$ \\
\hline Flap surgery & Single Limberg & 3 & $5.6(4-7)$ & $7.5(5-10)$ & $1.2(1.2-1.4)$ & $2.5(2-3.5)$ \\
\cline { 2 - 7 } & 2 Limberg & 13 & $6.3(5.3-9)$ & $10(7.4-12.5)$ & $1.45(1.2-1.7)$ & $1.5(1.1-2.1)$ \\
\cline { 2 - 7 } & 3 Limberg & 1 & 8 & 12 & 1.5 & 1.3 \\
\cline { 2 - 7 } & Bipedicled & 3 & $6(5-7)$ & $7.6(5-10)$ & $1.2(1-1.4)$ & $2.2(1.7-2.6)$ \\
\hline
\end{tabular}

$\mathrm{NA}=$ not applicable; $\mathrm{pts}=$ patients; $\mathrm{x}=$ defect width; $\mathrm{y}=$ defect height; $2 \mathrm{z}+\mathrm{x}=$ distance between posterior axillary lines. 
TABLE 2. Sizes of MMC defects, types of reconstruction, and complications

\begin{tabular}{llrlll}
\hline \multirow{2}{*}{ Type of Repair } & \multicolumn{1}{c}{ Type of Flap } & $\begin{array}{c}\text { No. of } \\
\text { Pts }\end{array}$ & Mean Defect Size in $\mathrm{cm}^{2}$ (range) & Complications \\
\hline Primary closure & NA & 30 & $46.9(28-60)$ & None \\
\hline Flap surgery & Single Limberg & 3 & $54.3(48-70)$ & 1 partial flap necrosis \\
\cline { 2 - 6 } & 2 Limberg & 13 & $69.2(39.2-112.5)$ & 2 minor flap tip necrosis \& 1 partial flap necrosis \\
\cline { 2 - 6 } & 3 Limberg & 1 & 96 & None \\
\cline { 2 - 5 } & Bipedicled & 3 & $47.6(25-70)$ & None & \\
\hline
\end{tabular}

tion is recommended for defects that are $>5 \mathrm{~cm}$ in diameter, but this is not suitable for all patients because of different weights and usable skin tissue on the back. We closed small defects not only with primary repair but also with flaps. We believe that defects should be considered based on ratios, not on sizes, and that all decisions on patients' reconstruction surgery should be made on an individual basis.

Because of tension-free repair and the lack of unnecessary flap use, we did not observe any complications in the patients who had primary closure. Our decision-making guide might be effective in determining the most suitable reconstruction technique. To prove its effectiveness, further comparative studies are necessary.

Postoperative complications following MMC wound closure are well described. ${ }^{10,11,14,15}$ Among the most common are CSF leak, meningitis, seroma, hematoma, skin flap necrosis, wound infection, and dehiscence. The average complication rates have been reported between $7.7 \%$ and $33 \% .{ }^{10,14,15,20}$ Our overall complication rate was only $8 \%$. Compared with the literature, this is very low; these results verified the reliability of our guide.

Our decision-making guide was developed by referring to our previous experience with MMC closure. To reduce wound complications, tension-free closure is the key element. To obtain this, knowledge of flap principles is mandatory. The use of a single defect width value is not sufficient for determining the correct reconstruction method. Complication ratios would be higher, similar to those reported in the literature, if such an approach was used. We believe that the success of a reconstruction is much more related to surgical planning in terms of deciding whether to use flaps or primary closure. According to our decision-making guide, other fasciocutaneous flaps can also be easily used, e.g., bilobed flaps, rotation flaps, advancement flaps, and so on.

\section{Conclusions}

Surgical repair of large MMCs may be a challenging problem. Because of various defect sizes and patient characteristics, no single protocol exists for reconstruction of the defect. To achieve successful outcomes, reconstruction planning should be done specifically for each patient. Our suggested decision-making guide might be effective in deciding which method is suitable for closure of MMC skin defects.
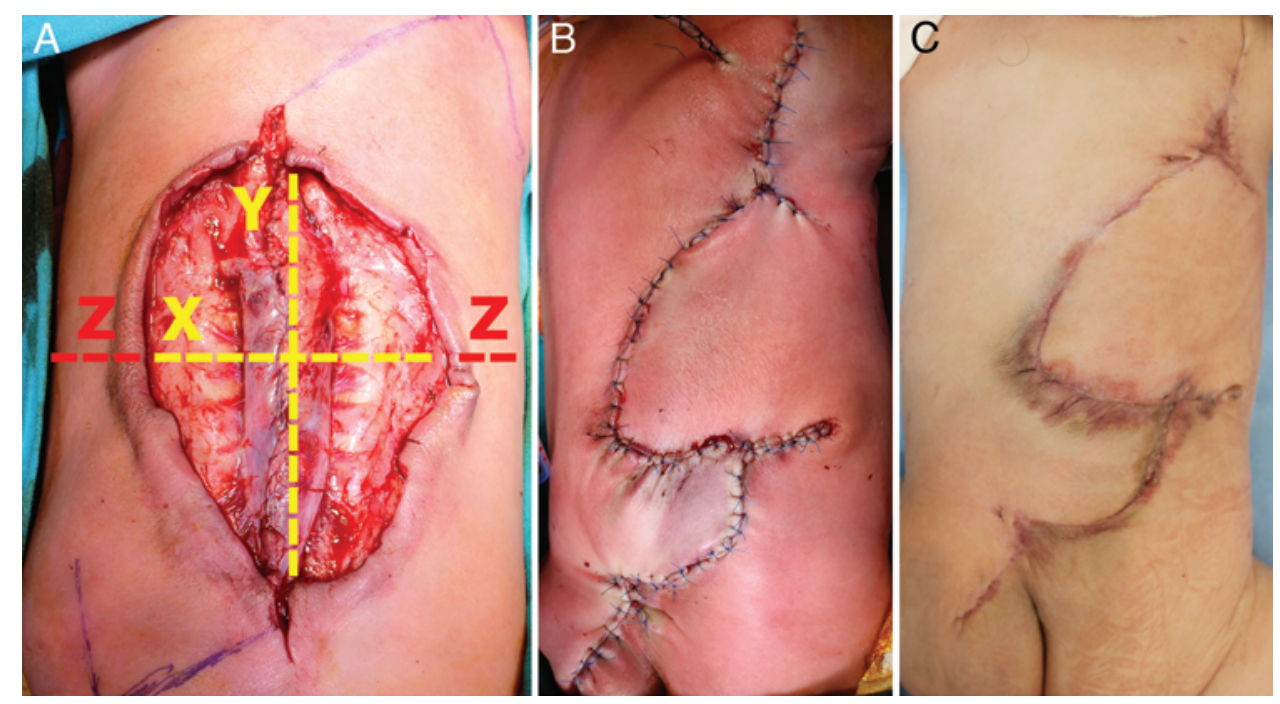

FIG. 2. Photographs of a 3-day-old girl with a large MMC in the thoracolumbar region. A: After neurosurgical repair, an intraoperative view shows the defect height $(\mathrm{y}) /$ width $(\mathrm{x})$ ratio $>1.5$ and the length between posterior axillary lines $(2 \mathrm{z}+\mathrm{x}) / \mathrm{defect}$ width $(x)<3$. According to our decision-making guide, 2 Limberg flaps were used to repair the defect. $B$ : An immediate postoperative view. C: Durable coverage is achieved over the neural tissues at 2 months postsurgery. Figure is available in color online only. 

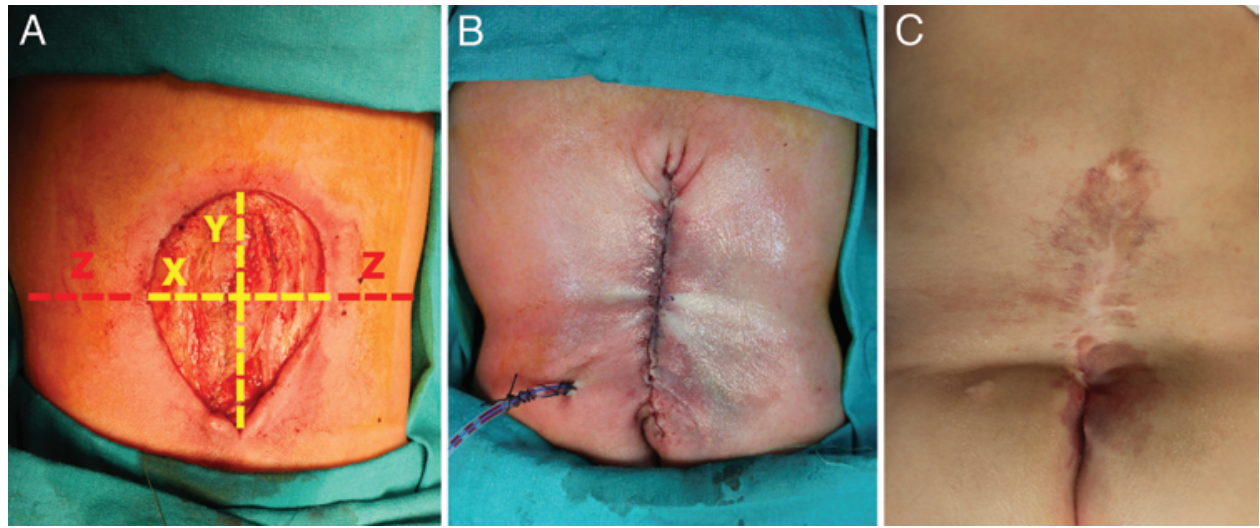

FIG. 3. Photographs of a 5-day-old boy with a large MMC in the lumbosacral region. A: After neurosurgical repair, an intraoperative view shows the defect height $(\mathrm{y}) /$ width $(\mathrm{x})$ ratio $>1.5$ and the length between posterior axillary lines $(2 \mathrm{z}+\mathrm{x}) /$ defect width $(\mathrm{x})$ $>3$. According to our decision-making guide, primary closure was performed. B: An immediate postoperative view. C: Durable coverage is achieved over the neural tissues at 4 months postsurgery. Figure is available in color online only.

\section{References}

1. Akan IM, Ulusoy MG, Bilen BT, Kapucu MR: Modified bilateral advancement flap: the slide-in flap. Ann Plast Surg 42:545-548, 1999

2. Bajaj PS, Welsh F, Shadid EA: Versatility of lumbar transposition flaps in the closure of meningomyelocele skin defects. Ann Plast Surg 2:103-108, 1979

3. Botto LD, Moore CA, Khoury MJ, Erickson JD: Neural-tube defects. N Engl J Med 341:1509-1519, 1999

4. Brau RH, Rodríguez R, Ramírez MV, González R, Martínez $\mathrm{V}$ : Experience in the management of myelomeningocele in Puerto Rico. J Neurosurg 72:726-731, 1990

5. Cruz NI, Ariyan S, Duncan CC, Cuono CB: Repair of lumbosacral myelomeningoceles with double Z-rhomboid flaps. Technical note. J Neurosurg 59:714-717, 1983

6. Davies D, Adendorff DJ: A large rotation flap raised across the midline to close lumbo-sacral meningomyelocoeles. Br J Plast Surg 30:166-168, 1977

7. Duffy FJ Jr, Weprin BE, Swift DM: A new approach to closure of large lumbosacral myelomeningoceles: the superior gluteal artery perforator flap. Plast Reconstr Surg 114:1864-1870, 2004

8. Greenberg M: Handbook of Neurosurgery. New York: Thieme, 2010, pp 114-116

9. Hayashi A, Maruyama Y: Bilateral latissimus dorsi V-Y musculocutaneous flap for closure of a large meningomyelocele. Plast Reconstr Surg 88:520-523, 1991

10. Kobraei EM, Ricci JA, Vasconez HC, Rinker BD: A comparison of techniques for myelomeningocele defect closure in the neonatal period. Childs Nerv Syst 30:1535-1541, 2014

11. Lanigan MW: Surgical repair of myelomeningocele. Ann Plast Surg 31:514-521, 1993

12. Lapid O, Rosenberg L, Cohen A: Meningomyelocele reconstruction with bilobed flaps. Br J Plast Surg 54:570-572, 2001

13. Luce EA, Stigers SW, Vandenbrink KD, Walsh JW: Splitthickness skin grafting of the myelomeningocele defect: a subset at risk for late ulceration. Plast Reconstr Surg 87:116-121, 1991

14. Luce EA, Walsh J: Wound closure of the myelomeningocoele defect. Plast Reconstr Surg 75:389-393, 1985

15. Mangels KJ, Tulipan N, Bruner JP, Nickolaus D: Use of bipe- dicular advancement flaps for intrauterine closure of myeloschisis. Pediatr Neurosurg 32:52-56, 2000

16. McCraw JB, Penix JO, Baker JW: Repair of major defects of the chest wall and spine with the latissimus dorsi myocutaneous flap. Plast Reconstr Surg 62:197-206, 1978

17. Ohtsuka H, Shioya N, Yada K: Modified Limberg flap for lumbosacral meningomyelocele defects. Ann Plast Surg 3:114-117, 1979

18. Patterson TJ: The use of rotation flaps following excision of lumbar myelo-meningoceles: an aid to the closure of large defects. Br J Surg 46:606-608, 1959

19. Reigel DH: Myelomeningocele, in Cheek WR (ed): Atlas of Pediatric Neurosurgery, ed 1. Philadelphia: WB Saunders, 1996, pp 1-9

20. Seidel SB, Gardner PM, Howard PS: Soft-tissue coverage of the neural elements after myelomeningocele repair. Ann Plast Surg 37:310-316, 1996

21. Ulusoy MG, Koçer U, Sungur N, Karaaslan O, Kankaya Y, Ozdemir R, et al: Closure of meningomyelocele defects with bilateral modified V-Y advancement flaps. Ann Plast Surg 54:640-644, 2005

\section{Disclosures}

The authors report no conflict of interest concerning the materials or methods used in this study or the findings specified in this paper.

\section{Author Contributions}

Conception and design: Kemaloğlu. Acquisition of data: Kemaloğlu, Özyazgan. Analysis and interpretation of data: all authors. Drafting the article: Kemaloğlu. Critically revising the article: Kemaloğlu, Özyazgan. Reviewed submitted version of manuscript: Kemaloğlu. Approved the final version of the manuscript on behalf of all authors: Kemaloğlu. Administrative/techni$\mathrm{cal} /$ material support: Kemaloğlu. Study supervision: Kemaloğlu.

\section{Correspondence}

Cemal Alper Kemaloğlu, Department of Plastic, Reconstructive, and Aesthetic Surgery, Erciyes University, Kayseri 38800, Turkey. email: dralperkemaloglu@yahoo.com. 